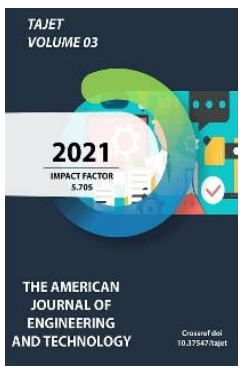

Copyright: Original content from this work may be used under the terms of the creative commons attributes 4.0 licence.

\section{Development Of High-Efficiency Extraction Equipment And Prospects For Industrial Application Of Extractors With Pneumatic Fluid Mixing}

\author{
Alimatov Bakhodir Abdumannonovich \\ Doctor Of Technical Sciences, Professor, Belgorod State Technological University Named After \\ V.G. Shukhov, Belgorod, Russia \\ Sadullaev Hamidullo Mansurovich \\ Senior Lecturer Of The Department Of Technological Machines And Equipment, Fergana \\ Polytechnic Institute, Fergana, Uzbekistan \\ Mamarizaev Ilkhomjon Mahmudovich \\ Master's Student, Fergana Polytechnic Institute, Fergana, Uzbekistan
}

\title{
ABSTRACT
}

The article provides a substantiation of the relevance of the development of highly efficient extraction equipment, shows the ways of intensification of liquid extraction processes, shows the device and principle of operation of the bubbling extractor developed by the authors, and the results of experimental studies of new designs of extractors at industrial enterprises.

\section{KEYWORDS}

Liquid extraction, extraction, process, apparatus, interface, intensification, pneumatic stirring, bubbling, column, stage, mixer, separator, concentric pipes, partitions, packing, overflow tubes, cap, light liquid, heavy liquid, inert gas, section, drops, splitting up.

\section{INTRODUCTION}

Liquid extraction processes, as the most effective methods for obtaining substances in a pure form, are widespread in the practice of various industries. Today it is impossible to imagine obtaining the majority of rare earth elements, noble metals, caprolactam, lysine and other valuable substances without liquid extraction; $100 \%$ of the sugar and vegetable oil 
consumed by mankind is produced using liquid extraction and extraction methods [1].

Along with a deep study of the process mechanism itself, great attention is paid to the development of highly efficient extraction equipment. The huge number of extractors developed to date is caused primarily by the fact that it is impossible to create an apparatus of a universal type, equally acceptable for processing a large number of liquid systems. However, the general line in the creation of intensified extractors is the introduction of external energy into the apparatus for the development of the interface of the contact of immiscible liquids.

\section{THE MAIN PART}

One of the ways to intensify the processes of liquid extraction is the use of the method of pneumatic mixing of liquids with a gas chemically inert with respect to the liquids being processed, and such devices have entered the technical literature under the name of bubbling extractors.
The results of our studies have shown that the optimal design is a bubbling extractor made in the form of a vertical multistage column, each stage of which is a mixer-settler.

Figure 1 shows the structure of the main elements and the principle of operation of the multi-stage bubble extractor developed by us [2].

Frame 1 of the extractor is divided by partitions 2 into separate settling sections. Mixing devices, consisting of inner 3 and outer 4 concentric pipes, are installed on partitions 2. Coaxially to pipes 3 and 4 , gas distribution nozzles 5 protruding under partitions 2 with holes 6 in the side walls are installed. In partitions 2, overflow tubes 7 are also attached, having holes 8 on the side of the lower plugged ends. From the top, tubes 7 are covered with caps 9 having slots 10 in the lower part and holes in the upper caps. 


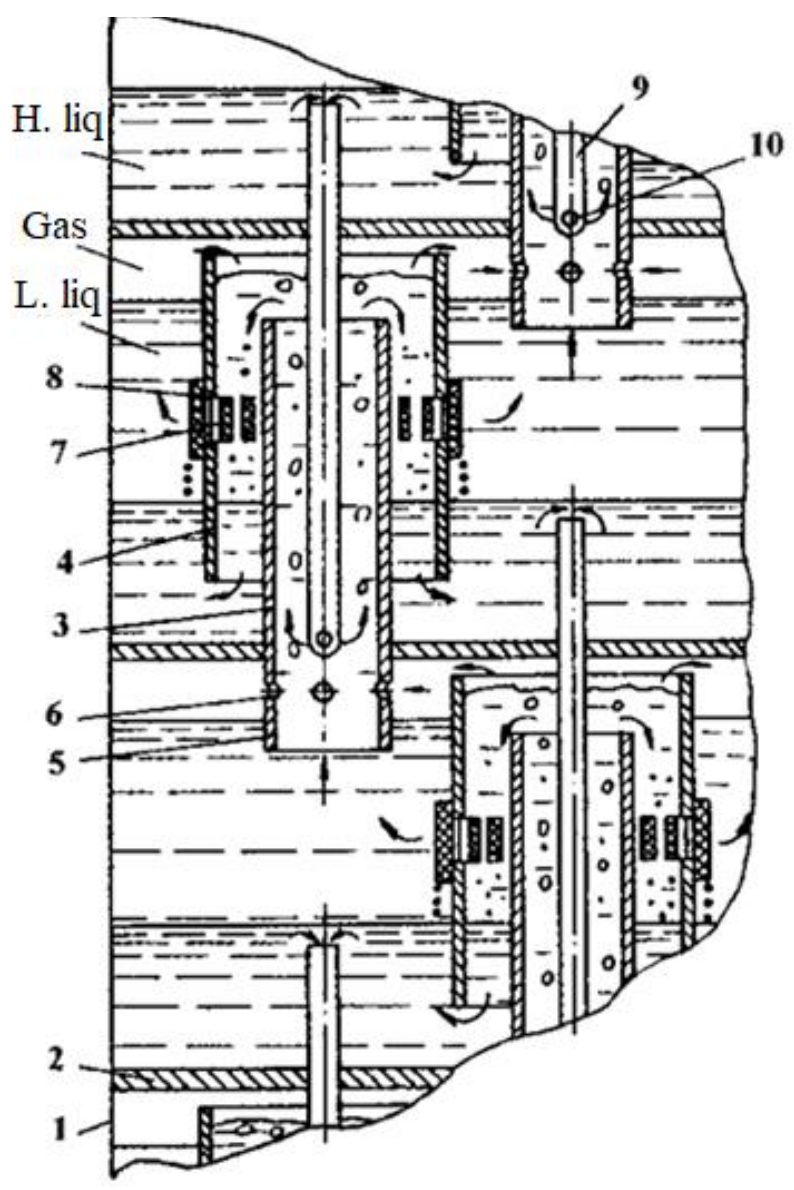

Fig. 1. The structure of the main elements and the principle of operation of the multi-stage bubble extractor

Light liquid enters the gas distribution nozzle 5 through its lower cut. Heavy liquid enters there through holes 8 in tubes 7 . When moving together from the bottom up inside the gas distribution nozzle 5 and then the branch pipe 3, the liquids are intensively mixed with a bubbling inert gas, which enters through the holes 6 of the gas distribution nozzle, and then collects under partition 2 and enters the overlying section.

The mixed liquids pass from top to bottom along with the annular space between the nozzles 3 and 4, exit into the settling part of the section, where the liquids are stratified. Drops of heavy liquid settle, forming a continuous layer on partition 2, from which the heavy liquid flows through the slots 10 into the tubes 7 and flows into the underlying section.

The main advantages of the extractor include:

- Simplicity and manufacturability of the apparatus design from the point of view of its manufacture;

- The fact that the apparatus has an unlimited capacity for liquids since any number of parallel working mixing elements can be installed in each stage;

- High efficiency of the process is achieved due to the direct flow of contacting fluids within each stage with a general countercurrent movement of fluids within the entire column [9]. 
An increase in the efficiency of the process is also facilitated by the crushing of one of the liquids into droplets in the mixing elements carried out in each stage, followed by their complete stratification in the settling part.

The indicated advantages of the described extractor made it possible to successfully use it in the industrial practice of the Grodno $\mathrm{p} / \mathrm{o}$ "Azot" (Republic of Belarus) for double extraction of caprolactam. At the first stage of extraction, caprolactam is extracted with benzene from lactam oil, at the second stage with water from benzene lactam. The total load on liquids is $45-50 \mathrm{~m}^{3} / \mathrm{m}^{2}$ hour, the consumption of inert gas (nitrogen) is $0.8-1 \mathrm{~m}^{3}$ per $1 \mathrm{~m}^{3}$ of processed liquids. The economic effect from the implementation of this development is more than 20 million rubles per year per unit.

For caprolactam production, where trichloroethylene is used as an extractant, we have developed another design of a bubbling extractor [3].
We have developed a number of bubble extractor designs specifically for use in specific industrial processes.

An extractor [4], which makes it possible to completely eliminate the carryover of droplets of a heavy liquid by a light flow, was proposed for the process of regeneration of acetic acid in the production of triacetyl cellulose (Fig. 2).

In industrial practice at Ferganaazot JSC, this technological process is carried out in extractors with sieve trays. Significant entrainment (7-8\% or more) of the aqueous phase by the flow of the etheric acid from the upper part of the extractor leads to a decrease in the quality of the etheric acid, and this, in turn, leads to excessive consumption of energy resources and semi-finished products at other stages of the technological process. In this case, the total specific load on liquids per extractor is only $19-19.2 \mathrm{~m} / \mathrm{m}^{2}$ hour, i.e. about $82 \%$ of the design. 


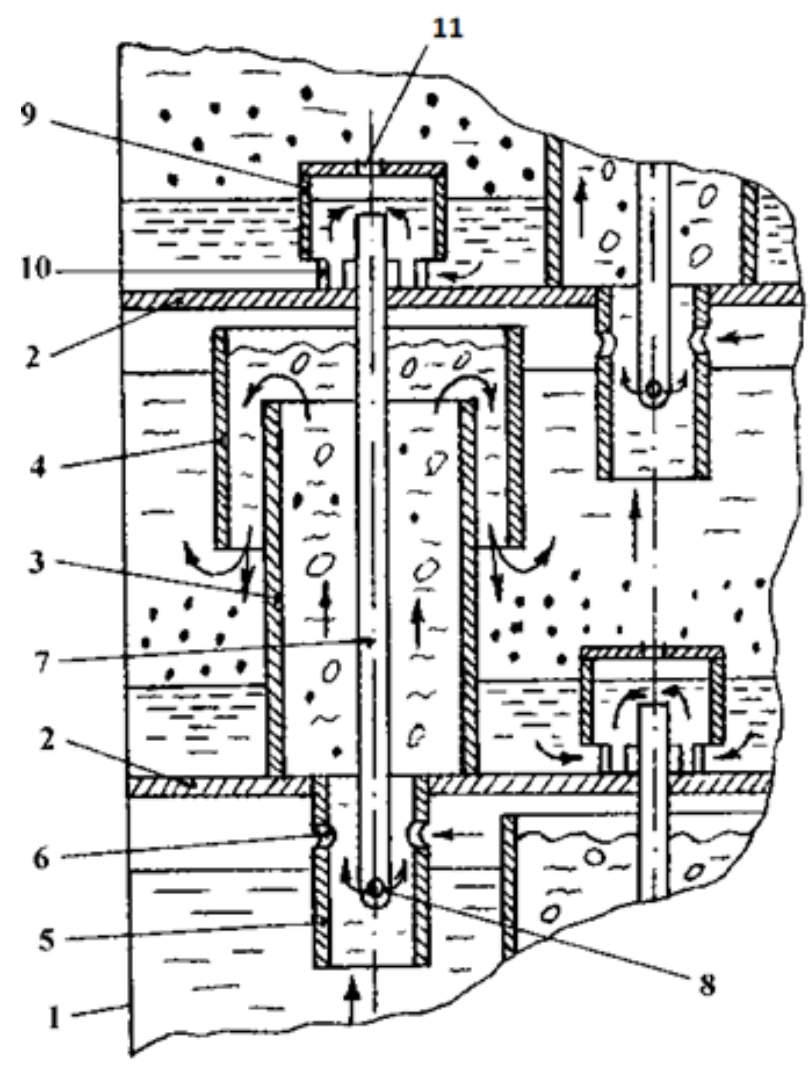

Fig. 2. Extractor

The advantages of the extractor we offer are as follows.

As a result of intensive mixing by inert gas bubbles inside the nozzle 3 (Fig. 2), the heavy liquid is crushed into drops, and the resulting mixture of liquids moves from top to bottom along the annular channel between the nozzles 3 and 4, where relatively large drops of heavy liquid due to gravitational and inertial forces settle in a continuous layer of heavy liquid. The uppercut of tubes 9 is located above the lower cut of nozzle 4, which ensures that a light liquid with small drops of heavy liquid leaves the mixing device only through holes 7 in nozzle 4 .

Overlapping holes 7 with a layer of fibrous material 8, well wetted by a light liquid, contributes to the formation of larger droplets of a heavy liquid in the layer of fibrous material due to coalescence. Coming out of the layer of fibrous material, coarse droplets of heavy liquid easily settle in the space between the mixing devices of the section.

The experiments were carried out by us in real production conditions on a model of a bubbling extractor, which had the following parameters: section height (extraction stage) - $400 \mathrm{~mm}$; the diameter of the inner branch pipe of the mixing device - $33 \mathrm{~mm}$; the diameter of the outer branch pipe of the mixing device - $50 \mathrm{~mm}$; inner diameter of the section $-104 \mathrm{~mm}$. As a fibrous material, we used a layer of fibreglass, covered on top for mechanical strength with a stainlesssteel mesh. 
The consumption of ethyl acetate was 0.08 $0.24 \mathrm{~m}^{3} / \mathrm{s}$, the consumption of an aqueous solution of acetic acid was $0.03-0.09 \mathrm{m3} / \mathrm{s}$; the maximum total specific load, in this case, was $30.5 \mathrm{~m}^{3} / \mathrm{m}^{2} /$ hour.

Nitrogen was used as an inert gas, the specific consumption of which did not exceed 1-1.2 $\mathrm{m}^{3}$ per $1 \mathrm{~m}^{3}$ of processed liquids.

The economic effect of this development is about 200 million rubles per year.

In order to increase the efficiency of the process by increasing the time of mixing liquids with a bubbling inert gas, we have developed a multistage extractor [5], proposed for use in the industrial process of purifying wastewater from phenols with benzene at the Fergana oil refinery [5-8].

The experiments were also carried out in real production conditions. The ratio of the phases "benzene-water" was maintained within 3:1, while the maximum water consumption was $0.13 \mathrm{~m}^{3} / \mathrm{h}$, and the maximum benzene consumption was $0.39 \mathrm{~m}^{3} / \mathrm{h}$. The three-stage model of the extractor made it possible to reduce the content of phenols in wastewater from 0.12 to $0.0007 \mathrm{~g} / \mathrm{l}$. The expected economic effect from the implementation of this development is more than 26 million rubs. in year.

\section{CONCLUSION}

For industrial systems requiring a long contact time of liquids with intensive pneumatic mixing, an extractor can be proposed, in which an increase in the contact time is carried out without increasing the height of the extractor stage. Finally, we have developed a design of a bubbling extractor with adjustable size of dispersed phase droplets obtained during crushing, which is very important for controlling the processes of mass transfer and ensuring maximum efficiency of the settling zones of the apparatus. Systemic studies carried out by us in recent years have made it possible to reveal the prospects of using bubbling extractors in biotechnology and hydrometallurgy.

\section{REFERENCES}

1. Vygon V.G., Mikheeva G.A. (1984). Extraction processes in liquid-solid and liquid-liquid systems. Results of Science and Technology. Processes and devices of chemical technology. M: VINITI, Volume 12, p. 98-182.

2. Alimatov B., Sadullaev Kh.M. Multi-stage bubble extractor. As. No. 912197 (USSR), BI No. 10, 1982

3. Alimatov B.A. Multi-stage bubble extractor. RUz patent No. 5013. Officer bull. (OB) No. 2.1998.

4. Alimatov B., Sokolov V.N., Kamoliddinov D.D., Sadullaev Kh.M., Tozhiev R.Zh. (1985). Bubble extractor. Certificate No. 1152609 (USSR). BI \# 16.

5. Alimatov B.A., Sokolov V.N., Sadullaev Kh.M., Karimov I.T. (1990). Multi-stage bubbling extractor. AS No. 1607859 (USSR), BI No. 43.

6. Alimatov B.A., Karimov I.T., Tozhiev R.Zh., Khursanov B.Zh. (1998). Multi-stage bubbling extractor. Patent RUz No. 5014. No. 2. 1998

7. Alimatov B.A. (1999). Bubble extractor. RUz patent No. 5681, BI No. 2.1999.

8. Alimatov B.A. and others. (2000). Development of structures, research and 
practical use of chemical and biotechnological equipment for processing heterogeneous media. Report on the State Scientific and Technological Progress. RUz. State per. No. 01.20 0009815, Inv. No. 02.20 0007171. Tashkent, SFSTI, $30 \mathrm{p}$.

9. Alimatov B.A., Sadullaev H.M., Karimov I.T. (2019). Methods for calculating and designing equipment for processing complex heterogeneous systems "liquidgas-liquid". Belgorod, $192 \mathrm{p}$. 